\title{
The impact of delayed blood centrifuging, choice of collection tube, and type of assay on 25-hydroxyvitamin D concentrations
}

\author{
Chu-Ling Yu, \\ Division of Cancer Epidemiology and Genetics, National Cancer Institute, National Institutes of \\ Health, Department of Health and Human Services, 6120 Executive Boulevard, Mailstop 7238, \\ Rockville, MD 20852, USA
}

Roni T. Falk,

Division of Cancer Epidemiology and Genetics, National Cancer Institute, National Institutes of Health, Department of Health and Human Services, 6120 Executive Boulevard, Mailstop 7238, Rockville, MD 20852, USA

\section{Michael G. Kimlin,}

Australian Sun and Health Research Laboratory, Institute of Health and Biomedical Innovation, Queensland University of Technology, Brisbane, QLD, Australia

\section{Preetha Rajaraman,}

Division of Cancer Epidemiology and Genetics, National Cancer Institute, National Institutes of Health, Department of Health and Human Services, 6120 Executive Boulevard, Mailstop 7238, Rockville, MD 20852, USA

\section{Alice J. Sigurdson,}

Division of Cancer Epidemiology and Genetics, National Cancer Institute, National Institutes of Health, Department of Health and Human Services, 6120 Executive Boulevard, Mailstop 7238, Rockville, MD 20852, USA

\section{Ronald L. Horst,}

R. L. Horst Heartland Assays, Inc., Ames, IA, USA

\section{Louis M. Cosentino,}

L. M. Cosentino Laboratory of Biospecimen and Biorepository Research, SAIC-Frederick Inc., NClFrederick, Frederick, MD, USA

Martha S. Linet, and Division of Cancer Epidemiology and Genetics, National Cancer Institute, National Institutes of Health, Department of Health and Human Services, 6120 Executive Boulevard, Mailstop 7238, Rockville, MD 20852, USA

\section{Michal Freedman}

Division of Cancer Epidemiology and Genetics, National Cancer Institute, National Institutes of Health, Department of Health and Human Services, 6120 Executive Boulevard, Mailstop 7238, Rockville, MD 20852, USA

\section{Abstract \\ Studies have examined the associations between cancers and circulating 25-hydroxyvitamin D [25 $(\mathrm{OH}) \mathrm{D}]$, but little is known about the impact of different laboratory practices on $25(\mathrm{OH}) \mathrm{D}$}


concentrations. We examined the potential impact of delayed blood centrifuging, choice of collection tube, and type of assay on $25(\mathrm{OH}) \mathrm{D}$ concentrations. Blood samples from 20 healthy volunteers underwent alternative laboratory procedures: four centrifuging times $(2,24,72$, and $96 \mathrm{~h}$ after blood draw); three types of collection tubes (red top serum tube, two different plasma anticoagulant tubes containing heparin or EDTA); and two types of assays (DiaSorin radioimmunoassay [RIA] and chemiluminescence immunoassay [CLIA/LIAISON®]). Log-transformed 25(OH)D concentrations were analyzed using the generalized estimating equations (GEE) linear regression models. We found no difference in $25(\mathrm{OH}) \mathrm{D}$ concentrations by centrifuging times or type of assay. There was some indication of a difference in $25(\mathrm{OH}) \mathrm{D}$ concentrations by tube type in CLIA/LIAISON®-assayed samples, with concentrations in heparinized plasma (geometric mean, $16.1 \mathrm{ng} \mathrm{ml}^{-1}$ ) higher than those in serum (geometric mean, $\left.15.3 \mathrm{ng} \mathrm{ml}^{-1}\right)(p=0.01)$, but the difference was significant only after substantial centrifuging delays $(96 \mathrm{~h}$ ). Our study suggests no necessity for requiring immediate processing of blood samples after collection or for the choice of a tube type or assay.

\section{Keywords}

Vitamin D; 25-hydroxyvitamin D; Specimen handling; Time factors; Epidemiologic methods

\section{Introduction}

Some epidemiologic studies [1-4], although not all [5-8], have suggested inverse associations between vitamin D concentrations and certain cancers. Studies of vitamin D have generally focused on circulating 25-hydroxyvitamin D [25(OH)D] as the ideal biomarker for vitamin D status. However, little is known about the impact of laboratory practices on $25(\mathrm{OH}) \mathrm{D}$ concentrations. Concerns have been raised regarding whether these differences affect the comparability of results across studies. In addition, if sample preparation practices differed by disease status (e.g., controls undergo more shipping delays than cases and thus have a longer lag between blood draw and centrifuging), and these differences affected $25(\mathrm{OH}) \mathrm{D}$ concentrations, differential bias might result.

Epidemiologic studies of $25(\mathrm{OH}) \mathrm{D}$ vary in several laboratory practices that might affect 25 $(\mathrm{OH}) \mathrm{D}$ concentrations, including (1) the time from blood draw to centrifuging, (2) choice of collection tube, and (3) type of 25(OH)D assay. For instance, in the Nurses' Health Study, unprocessed blood samples were collected in tubes containing heparin as an anticoagulant and returned to their centralized facility via overnight shipping, with $97 \%$ of samples received within $26 \mathrm{~h}$ of draw for processing [1]. The Health Professionals Follow-Up study, which also processed blood samples at a centralized facility after overnight shipping, collected blood samples in tubes containing the anticoagulant sodium EDTA [9]. In the Prostate, Lung, Colorectal and Ovarian (PLCO) Cancer Screening Trial, blood samples were collected in multiple tube types with 25(OH)D concentrations measured using samples collected in red top serum tubes, which were centrifuged within $2 \mathrm{~h}$ of blood draw (Mark Purdue, personal communication). Concerns have been raised regarding whether different blood processing procedures affect $25(\mathrm{OH}) \mathrm{D}$ measurements. Some have questioned whether delayed centrifuging reduces $25(\mathrm{OH}) \mathrm{D}$ stability due to hemolysis [10]. In addition, the choice of collection tube has been shown to affect the measurement for many analytes [11].

A number of laboratory methods exist for $25(\mathrm{OH}) \mathrm{D}$ measurements, including the radioimmunoassay (RIA), competitive protein binding assays (CPBA), direct detection methodologies (e.g., high performance liquid chromatography [HPLC] and liquid chromatography-tandem mass spectroscopy [LC-MS/MS]), and automatic instrumentation methodologies (e.g., The DiaSorin LIAISON $®$ platform and the Nicols Advantage ${ }^{\circledR}$ System) $[12,13]$. Among these methods, DiaSorin RIA has been commonly used in large-scale 
epidemiologic studies. In recent years, there has been increasing interest in applying automated $25(\mathrm{OH}) \mathrm{D}$ assays, such as the DiaSorin chemiluminescence immunoassay (CLIA/LIAISON®), in epidemiologic studies. However, information on comparability of $25(\mathrm{OH}) \mathrm{D}$ measurements across different assays remains limited.

To address these issues, we conducted a methods study to systematically evaluate the potential impact on 25(OH)D concentrations from the time from blood draw to centrifuging $(2,24,72$, and $96 \mathrm{~h}$ after blood draw), choice of collection tubes (red top serum tube, two different anticoagulant tubes containing heparin or EDTA), as well as two of the most commonly used assays in epidemiologic studies (DiaSorin RIA and CLIA/LIAISON®).

\section{Materials and methods}

\section{Study population}

The institutional review board at the National Cancer Institute approved the protocol. In March 2008, 20 healthy volunteers (and two additional volunteers for quality control) were enrolled in Maryland, USA. To increase the range of $25(\mathrm{OH}) \mathrm{D}$ concentrations, we enrolled volunteers of various racial groups/skin tones and included a subset of persons who had recently taken a sunny holiday in low latitudes (e.g., Florida, the Caribbean) because cutaneous production of vitamin $\mathrm{D}$ is related to the melanin content of the skin and recent sun exposure [2]. The recruiting center provided the following information on the 20 anonymous volunteers ( 7 males and 13 females; mean age $=46.3$ years, range $26-63$ years): 10 Caucasians/light skin individuals (6 with recent sunny holiday trips), and 10 non-Caucasians/nonlight skin individuals (3 with recent sunny holiday trips).

\section{Blood processing}

We collected donor samples into three tube types: red top serum tubes (no additive), greentopped plasma tubes (heparin as additive), and lavender-topped plasma tubes (EDTA as additive) (Fig. 1). Samples were randomized to avoid any potential bias from the order of collection and were subsequently assigned to one of each centrifuging times to simulate several field conditions-immediate processing ( $2 \mathrm{~h}$ ), overnight shipping ( $24 \mathrm{~h})$, weekend shipping (72 h), and delayed receipt of blood samples ( $96 \mathrm{~h}$ ). Except for the samples centrifuged at $2 \mathrm{~h}$ after blood draw, which were retained on wet ice until centrifuging, other samples were placed in plastic canisters surrounded by $-20^{\circ} \mathrm{C}$ gel-packs and stored in shipping boxes until centrifuging, to maintain the samples between 2 and $8^{\circ} \mathrm{C}$ until centrifugation. All blood samples were centrifuged at $1,200 \times g$ for $15 \mathrm{~min}$ at $10^{\circ} \mathrm{C}$, aliquoted and stored at $-70^{\circ} \mathrm{C}$ until shipment to Heartland Assays (Ames, IA) for 25(OH)D measurement. There were a total of 24 tubes from each volunteer ( 4 centrifuging times by 3 collection tube types by 2 assays).

\section{5(OH)D assays}

Measurement of 25(OH)D was taken at one laboratory using CLIA/LIAISON® and RIA (both performed at Heartland Assays using commercially available kits from DiaSorin [Stillwater, MN]). The DiaSorin LIAISON® 25-OH vitamin D Total Assay System was used for the CLIA/ LIAISON® assay. Details of the two assays have been described previously $[14,15]$. The limit of detection was $4.0 \mathrm{ng} \mathrm{ml}^{-1}$ for CLIA/LIAISON® and $2.5 \mathrm{ng} \mathrm{ml}^{-1}$ for DiaSorin RIA (for conversion to $\mathrm{nmol}^{-1}, 1 \mathrm{ng} \mathrm{ml}^{-1}=2.496 \mathrm{nmol}^{-1}$ ). For both assays, each batch contained up to 100 samples. Thus, our samples were analyzed in three batches with samples from each volunteer included in the same batch. One laboratory investigator $(\mathrm{RH})$, blinded to the centrifuging time and the type of sample, oversaw all laboratory analyses. 


\section{Quality control (QC)}

We were allowed to include only a limited number of QC samples given our budget and the number of samples per batch. We decided to maximize the number of heparin tubes that were centrifuged at $2 \mathrm{~h}$ based on recommendations from other investigators. One $\mathrm{QC}$ volunteer was enrolled, with the volunteer's blood collected in heparin tubes and centrifuged after $2 \mathrm{~h}$.

Samples from this QC volunteer were included as duplicates in each batch (for both RIA and CLIA/LIAISON®) to provide variance estimates associated with within- and between-batch variability. The statistical estimation procedure we used estimated all coefficient of variation (CV) parameters at one time. The within-batch and between-batch CV for CLIA/LIAISON® were 5.2 and $6.1 \%$, respectively. For RIA, the within-batch CV was $11.1 \%$, whereas the between-batch $\mathrm{CV}$ was outside our statistical constraint (we constrained this to 0 ), suggesting that the differences within batch accounted for all the measurable variability in RIA.

\section{Statistical analysis}

$25(\mathrm{OH}) \mathrm{D}$ concentrations were logarithmically transformed, and the Pearson correlation coefficient $(r)$ was calculated to examine the agreement between the concentrations measured by CLIA/LIAISON ${ }^{\circledR}$ and RIA. To assess the effects of delayed centrifuging time, type of collection tube, and type of $25(\mathrm{OH}) \mathrm{D}$ assay, we used generalized estimating equations (GEE) linear regression models [16], which account for the correlations between measures from the same individual, with the log-transformed $25(\mathrm{OH}) \mathrm{D}$ results as continuous outcomes. Explanatory variables included centrifuging time (four categories), collection tube (three categories), and type of $25(\mathrm{OH}) \mathrm{D}$ assay (two categories). Interaction between collection tube and centrifuging time on $25(\mathrm{OH}) \mathrm{D}$ concentrations was evaluated by creating cross-product terms. A priori, we decided to examine the effect of collection tube at the 2-hour and the 24hour centrifuging times, because they are common times before processing. All statistical tests were two-sided and performed using the SAS ${ }^{\circledR}$ statistical software (Cary, NC).

\section{Results}

\section{Distribution of 25(OH)D concentrations}

The $25(\mathrm{OH}) \mathrm{D}$ concentrations in our study were generally lower than the proposed guideline of $20 \mathrm{ng} \mathrm{ml}^{-1}$ (or $50 \mathrm{nmoll}^{-1}$ ) [17] (Table 1). The two assays gave comparable 25(OH)D values (Table 1), and the correlation between the two assays was high $(r=0.89)$. In addition, the type of assay had little effect on 25(OH)D concentrations in the GEE model (omnibus test, $p=0.37$ ), after adjusting for centrifuging time and collection tube.

\section{CLIA/LIAISON®}

None of the 25(OH)D concentrations in our samples were below or close to the limit of detection (minimum, $5.4 \mathrm{ng} \mathrm{ml}^{-1}$ vs. limit of detection, $4.0 \mathrm{ng} \mathrm{ml}^{-1}$ ). We found no evidence of the effect of centrifuging time on 25(OH)D concentrations (Table 2). We found some indication of a difference in $25(\mathrm{OH}) \mathrm{D}$ concentrations by type of collection tube (Table 2). Pairwise comparisons between tubes revealed that heparinized plasma had significantly higher 25 $(\mathrm{OH}) \mathrm{D}$ concentrations than serum (pair-wise test, $p=0.01$ ) and marginally non-significantly higher concentrations than EDTA plasma (pair-wise test, $p=0.08$ ). The difference by tube was statistically significant only in samples centrifuged at $96 \mathrm{~h}$ (omnibus test, $p=0.05$ ) but not in samples centrifuged earlier, including the two centrifuging times ( 2 and $24 \mathrm{~h}$ ) commonly used in large epidemiologic studies (data not presented). No significant interactions were found between centrifuging time and collection tube (data not presented). 


\section{RIA}

None of the 25(OH)D concentrations in our samples were below or close to the limit of detection (minimum, $5.1 \mathrm{ng} \mathrm{ml}^{-1}$ vs. limit of detection, $2.5 \mathrm{ng} \mathrm{ml}^{-1}$ ). Although we found a marginally significant effect of centrifuging time on $25(\mathrm{OH}) \mathrm{D}$ concentrations, there was no evidence of a consistent trend (decreasing or increasing) across time (Table 2). Furthermore, we found no differences in $25(\mathrm{OH}) \mathrm{D}$ concentrations between samples centrifuged at 2 and 24 $\mathrm{h}$ (pair-wise test, $p=0.91$ ), the two most commonly used centrifuging times in epidemiologic studies. We found little effect of collection tube on 25(OH)D concentrations (Table 2). No significant differences between tubes were found in the sub-analyses of samples centrifuged at 2 or $24 \mathrm{~h}$ (data not presented). There was no evidence of interaction between centrifuging time and collection tube (data not presented).

\section{Discussion}

In this study, we found no evidence of a consistent trend across centrifuging times in $25(\mathrm{OH})$ D concentrations, up to $96 \mathrm{~h}$ after blood collection. Neither did we find significant differences in $25(\mathrm{OH}) \mathrm{D}$ concentrations by assay type. There was some indication of a difference in 25 $(\mathrm{OH}) \mathrm{D}$ concentrations by tube type in CLIA/LIAISON $®$-assayed samples, but the difference was statistically significant only after substantial centrifuging delays $(96 \mathrm{~h})$, with concentrations in heparinized plasma higher than in serum or EDTA plasma.

There has been little information about the potential impact of blood collection tubes on 25 $(\mathrm{OH}) \mathrm{D}$ concentrations. Although there was a marginally significant effect of tube type using CLIA/LIAISON®, our finding should be interpreted with caution. The effect was evident only in CLIA/LIAISON ${ }^{\circledR}$-assayed samples and was not significant in the most relevant centrifuging times for large epidemiologic studies ( 2 and $24 \mathrm{~h}$ ). Furthermore, the differences in 25(OH)D concentrations by collection tube were not large (Table 1) and may not be physiologically significant. Our null finding is consistent with a previous study [18], which found no effect of collection tube on 25(OH)D using an assay developed by Mason and Posen [19]. Ersfeld et al. [14] also found no difference in 25(OH)D concentrations between serum and EDTA plasma using CLIA/LIAISON®, but the authors did not include heparinized plasma in their study. To our knowledge, our study is the first to systematically evaluate the potential impact of collection tube on 25(OH)D concentrations when using DiaSorin RIA, one of the most commonly used $25(\mathrm{OH}) \mathrm{D}$ assays in epidemiologic studies.

A prolonged time between blood draw and centrifuging could increase hemolysis [10], which could impair the stability of 25(OH)D molecules. Lissner et al. [18] reported that $25(\mathrm{OH}) \mathrm{D}$ is stable in uncentrifuged blood until $72 \mathrm{~h}$, using an assay developed by Mason and Posen [19]. To our knowledge, no previous study has evaluated the stability of $25(\mathrm{OH}) \mathrm{D}$ in uncentrifuged blood across time using commonly used $25(\mathrm{OH}) \mathrm{D}$ assays. We detected a marginally significant difference in 25(OH)D concentrations over time in DiaSorin RIA-assayed samples, but the absence of a consistent time trend in $25(\mathrm{OH}) \mathrm{D}$ concentrations does not support an effect of centrifuging time. Specifically, we did not detect differences in 25(OH)D concentrations between samples centrifuged at 2 and $24 \mathrm{~h}$, suggesting that overnight shipping of unprocessed blood samples is acceptable in large geographically diverse epidemiologic studies.

Among all commonly used 25(OH)D assays, DiaSorin RIA has been predominantly used for 25(OH)D quantification in large-scale epidemiologic studies [13], but recently, automated technology such as the CLIA/LIAISON® platform has gained wide acceptance in large clinical laboratories in the United States. [13,14]. Our finding that the two assays give comparable 25 $(\mathrm{OH}) \mathrm{D}$ results is consistent with previous studies [14,20,21]. Ersfeld et al. [14] reported a high correlation between the results of the two assays in 329 clinical samples $(r=0.91)$. Similarly, a recent study reported a strong correlation $(r=0.918)$ between the two assays using 390 serum 
samples from a clinical trial of vitamin $\mathrm{D}_{3}$ supplement [21]. In an analysis of 228 osteoporotic patients, Souberbielle et al. also reported a high correlation between the assays $(r=0.83)$. The authors also suggested that the DiaSorin RIA gives higher 25(OH)D readings than CLIA/ LIAISON® at lower concentrations, whereas the CLIA/LIAISON $®$ assay gives higher readings at high concentrations [20].

Several limitations should be considered. First, most of the 25(OH)D concentrations in the 20 volunteers were at levels proposed to be clinically insufficient $\left(<20 \mathrm{ng} \mathrm{ml}^{-1}\right.$ or $<30 \mathrm{ng} \mathrm{ml}^{-1}$, in the absence of agreement on optimal concentrations) [17,22], and therefore, the generalizability of our findings to higher concentrations is not known. Also, this study was not designed to evaluate laboratory reliability, although with the blinded repeat samples we were able to calculate within-batch CVs, which were acceptable. Other limitations include the small sample size, which precluded some subgroup analyses and the detection of interactions, and multiple comparisons.

In conclusion, two commonly used 25(OH)D assays, CLIA/LIAISON® and DiaSorin RIA, gave comparable results, and longer intervals between blood draw and centrifuging did not influence $25(\mathrm{OH}) \mathrm{D}$ concentrations. There were some indications that $25(\mathrm{OH}) \mathrm{D}$ concentrations in heparinized plasma may be higher than in serum or EDTA plasma, particularly when using CLIA/LIAISON®, but the difference was not significant within normal time frames between collection and centrifuging. Our study suggests no necessity for requiring immediate processing of blood samples after collection or choice of one type of $25(\mathrm{OH}) \mathrm{D}$ assay or blood collection tube. Future studies with a wider range of $25(\mathrm{OH}) \mathrm{D}$ concentrations and larger sample sizes could be helpful in confirming our findings.

\section{Acknowledgments}

We thank Dr. Barry Graubard for his statistical advice and Ms. Elaine Gunter for study consultation.

Funding: This research was supported by the Intramural Research Program of the National Institutes of Health and the National Cancer Institute, and by federal funds from the National Cancer Institute, National Institutes of Health, under Contract NO1-CO-12400. The content of this publication does not necessarily reflect the views or policies of the Department of Health and Human Services nor does mention of trade names, commercial products, or organization imply endorsement by the United States Government.

\section{References}

1. Bertone-Johnson ER, Chen WY, Holick MF, et al. Plasma 25-hydroxyvitamin D and 1,25dihydroxyvitamin D and risk of breast cancer. Cancer Epidemiol Biomarkers Prev 2005;14:19911997. [PubMed: 16103450]

2. Giovannucci E. The epidemiology of vitamin D and cancer incidence and mortality: a review (United States). Cancer Causes Control 2005;16:83-95. [PubMed: 15868450]

3. Giovannucci E. Vitamin D and cancer incidence in the Harvard cohorts. Ann Epidemiol 2009;19:8488. [PubMed: 18291673]

4. Giovannucci E, Liu Y, Rimm EB, et al. Prospective study of predictors of vitamin D status and cancer incidence and mortality in men. J Natl Cancer Inst 2006;98:451-459. [PubMed: 16595781]

5. Ahn J, Peters U, Albanes D, et al. Serum vitamin D concentration and prostate cancer risk: a nested case-control study. J Natl Cancer Inst 2008;100:796-804. [PubMed: 18505967]

6. Faupel-Badger JM, Diaw L, Albanes D, Virtamo J, Woodson K, Tangrea JA. Lack of association between serum levels of 25-hydroxyvitamin D and the subsequent risk of prostate cancer in Finnish men. Cancer Epidemiol Biomarkers Prev 2007;16:2784-2786. [PubMed: 18086789]

7. Freedman DM, Looker AC, Chang SC, Graubard BI. Prospective study of serum vitamin D and cancer mortality in the United States. J Natl Cancer Inst 2007;99:1594-1602. [PubMed: 17971526] 
8. Tworoger SS, Lee IM, Buring JE, Rosner B, Hollis BW, Hankinson SE. Plasma 25-hydroxyvitamin D and 1,25-dihydroxyvitamin D and risk of incident ovarian cancer. Cancer Epidemiol Biomarkers Prev 2007;16:783-788. [PubMed: 17416771]

9. Platz EA, Leitzmann MF, Hollis BW, Willett WC, Giovannucci E. Plasma 1,25-dihydroxy- and 25hydroxyvitamin D and subsequent risk of prostate cancer. Cancer Causes Control 2004;15:255-265. [PubMed: 15090720]

10. Landi MT, Caporaso N. Sample collection, processing and storage. IARC Sci Publ 1997;142:223236. [PubMed: 9354922]

11. Tworoger SS, Hankinson SE. Collection, processing, and storage of biological samples in epidemiologic studies: sex hormones, carotenoids, inflammatory markers, and proteomics as examples. Cancer Epidemiol Biomarkers Prev 2006;15:1578-1581. [PubMed: 16985015]

12. Binkley N, Krueger D, Gemar D, Drezner MK. Correlation among 25-hydroxy-vitamin D assays. J Clin Endocrinol Metab 2008;93:1804-1808. [PubMed: 18319318]

13. Hollis BW, Horst RL. The assessment of circulating $25(\mathrm{OH}) \mathrm{D}$ and $1,25(\mathrm{OH})_{2} \mathrm{D}$ : where we are and where we are going. J Steroid Biochem Mol Biol 2007;103:473-476. [PubMed: 17197173]

14. Ersfeld DL, Rao DS, Body JJ, et al. Analytical and clinical validation of the $25 \mathrm{OH}$ vitamin D assay for the LIAISON automated analyzer. Clin Biochem 2004;37:867-874. [PubMed: 15369717]

15. Hollis BW, Kamerud JQ, Selvaag SR, Lorenz JD, Napoli JL. Determination of vitamin D status by radioimmunoassay with an ${ }^{125}$ I-labeled tracer. Clin Chem 1993;39:529-533. [PubMed: 8448871]

16. Zeger SL, Liang KY. Longitudinal data analysis for discrete and continuous outcomes. Biometrics 1986;42:121-130. [PubMed: 3719049]

17. Holick MF. Vitamin D deficiency. N Engl J Med 2007;357:266-281. [PubMed: 17634462]

18. Lissner D, Mason RS, Posen S. Stability of vitamin D metabolites in human blood serum and plasma. Clin Chem 1981;27:773-774. [PubMed: 7226510]

19. Mason RS, Posen S. Some problems associated with assay of 25-hydroxycalciferol in human serum. Clin Chem 1977;23:806-810. [PubMed: 856487]

20. Souberbielle JC, Fayol V, Sault C, Lawson-Body E, Kahan A, Cormier C. Assay-specific decision limits for two new automated parathyroid hormone and 25-hydroxyvitamin D assays. Clin Chem 2005;51:395-400. [PubMed: 15563480]

21. Wagner D, Hanwell HE, Vieth R. An evaluation of automated methods for measurement of serum 25-hydroxyvitamin D. Clin Biochem 2009;42:1549-1556. [PubMed: 19631201]

22. Heaney RP. The vitamin D requirement in health and disease. J Steroid Biochem Mol Biol 2005;97:13-19. [PubMed: 16026981] 
Day 1 (Monday): Venipuncture; partially fill an $8 \mathrm{ml}$ red top serum tube and discard (pre-collection 9 am to capture and eliminate epithelial cells); then start collecting samples following the appropriate order to avoid cross contamination

$9-11$ am
11 am
(2 hour test)
$\frac{\text { Day } 2 \text { (Tuesday): }}{9 \text { am }}$

(24 hour test)

Day 4 (Thursday): 9 am

(72 hour test)

Day 5 (Friday): 9 am

(96 hour test)
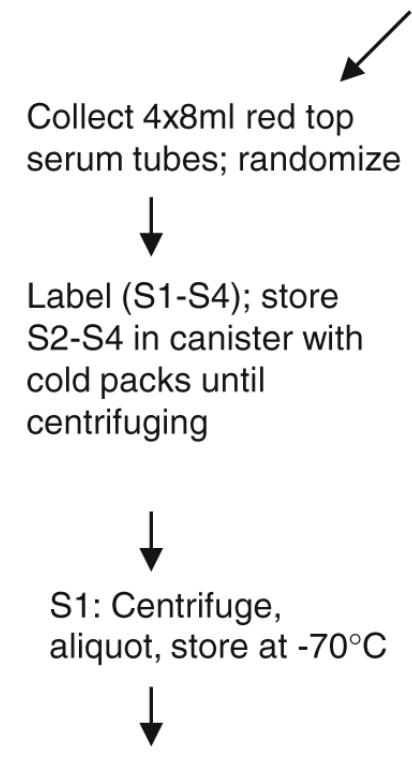

S2: Centrifuge, aliquot, store at $-70^{\circ} \mathrm{C}$

S3: Centrifuge, aliquot, store at $-70^{\circ} \mathrm{C}$

S4: Centrifuge, aliquot, store at $-70^{\circ} \mathrm{C}$

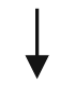

Collect $2 \times 8 \mathrm{ml}$ heparin tubes

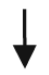

Combine tubes, and then split into 4 aliquots $(\mathrm{H} 1-\mathrm{H} 4)$; store $\mathrm{H} 2-\mathrm{H} 4$ in canister with cold packs until centrifuging

$\mathrm{H} 1$ : Centrifuge, aliquot, store at $-70^{\circ} \mathrm{C}$

$\mathrm{H} 2$ : Centrifuge, aliquot, store at $-70^{\circ} \mathrm{C}$

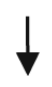

H3: Centrifuge, aliquot, store at $-70^{\circ} \mathrm{C}$

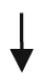

H4: Centrifuge, aliquot, store at $-70^{\circ} \mathrm{C}$

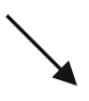

Collect 3x6ml EDTA tubes

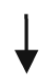

Combine tubes, and then split into 4 aliquots (E1-E4); store E2-E4 in canister with cold packs until centrifuging

E1: Centrifuge, aliquot, store at $-70^{\circ} \mathrm{C}$

E2: Centrifuge, aliquot, store at $-70^{\circ} \mathrm{C}$

E3: Centrifuge, aliquot, store at $-70^{\circ} \mathrm{C}$

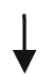

E4: Centrifuge, aliquot, store at $-70^{\circ} \mathrm{C}$

Monday
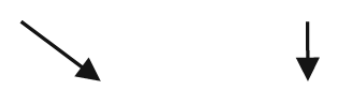

Send samples to Heartland assays ( 3 tube types by 4 centrifuging times by 2 assays; resulting in 24 samples per volunteer); shipment on dry ice

*All samples were anonymized; any coding of the samples will not provide linking to the identity of donors.

Fig. 1.

Blood sample collection and processing in 20 study volunteers 


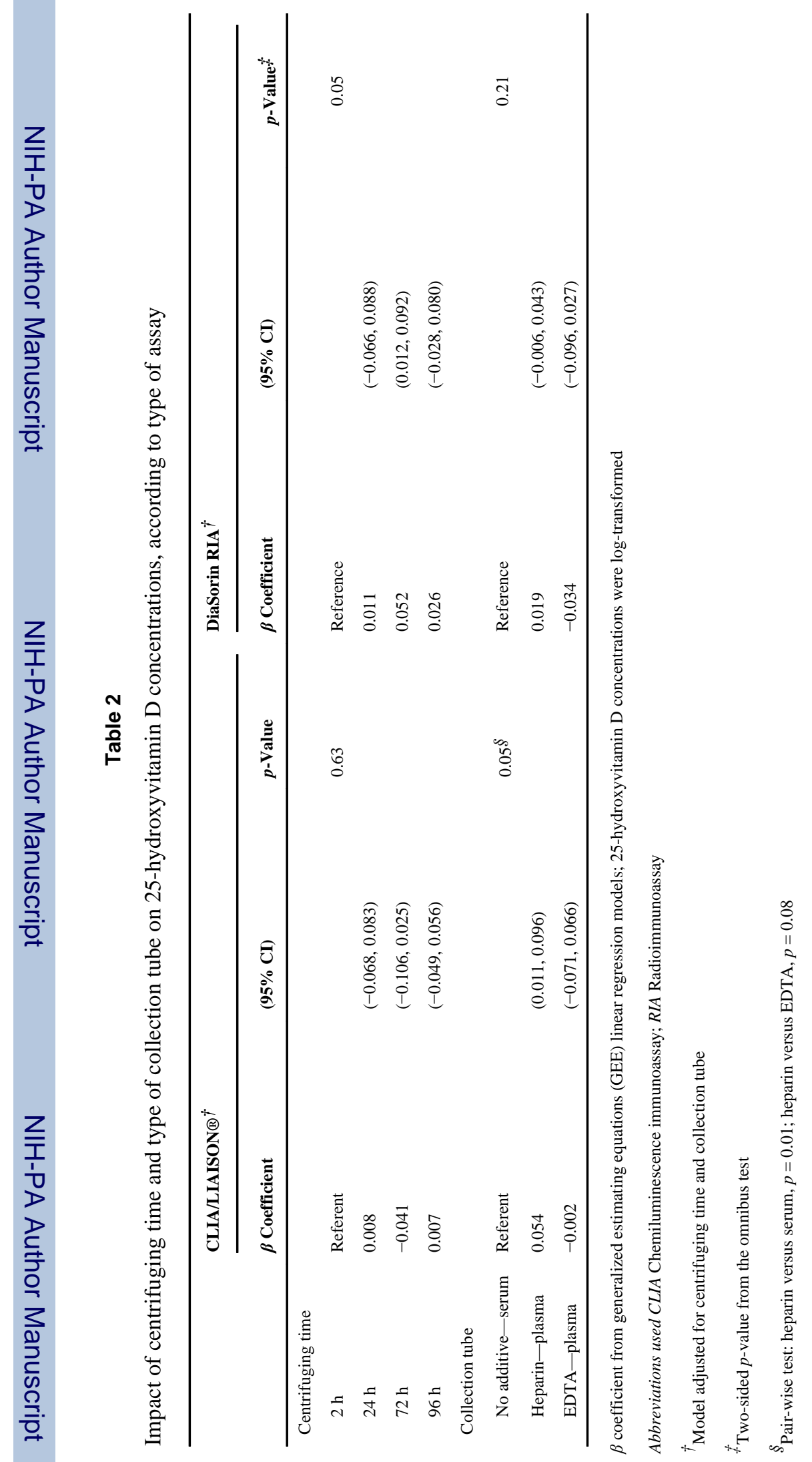

Cancer Causes Control. Author manuscript; available in PMC 2011 April 1. 